\title{
M148R and M149R are two virulence factors for myxoma virus pathogenesis in the European rabbit
}

\author{
Sophie Blanié ${ }^{1,2}$, Jérémy Mortier ${ }^{1,2}$, Maxence Delverdier ${ }^{1,2}$, \\ Stéphane Bertagnoli ${ }^{1,2}$, Christelle CAMus-Bouclainville ${ }^{1,2 *}$ \\ ${ }^{1}$ INRA, UMR 1225, F-31076 Toulouse, France \\ ${ }^{2}$ Université de Toulouse ; ENVT ; UMR 1225 ; F-31076 Toulouse, France
}

(Received 25 July 2008; accepted 13 November 2008)

\begin{abstract}
Myxoma virus (MYXV), a member of the Poxviridae family, is the agent responsible for myxomatosis, a fatal disease in the European rabbit (Oryctolagus cuniculus). MYXV has a linear double-stranded DNA genome that encodes several factors important for evasion from the host immune system. Among them, four ankyrin (ANK) repeat proteins were identified: M148R, M149R, M150R and M-T5. To date, only M150R and M-T5 were studied and characterized as critical virulence factors. This article presents the first characterization of M148R and M149R. Green Fluorescent Protein (GFP) fusions allowed us to localize them in a viral context. Whereas M149R is only cytoplasmic, interestingly, M148R is in part located in the nucleolus, a unique feature for an ANK repeat poxviral protein. In order to evaluate their implication in viral pathogenicity, targeted M148R, M149R, or both deletions were constructed in the wild type T1 strain of myxoma virus. In vitro infection of rabbit and primate cultured cells as well as primary rabbit cells allowed us to conclude that M148R and M149R are not likely to be implicated in cell tropism or host range functions. However, in vivo experiments revealed that they are virulence factors since after infection of European rabbits with mutant viruses, a delay in the onset of clinical signs, an increase of survival time and a dramatic decrease in mortality rate were observed. Moreover, histological analysis suggests that M148R plays a role in the subversion of host inflammatory response by MYXV.
\end{abstract}

poxvirus / myxoma virus / ankyrin repeat / virulence / rabbit

\section{INTRODUCTION}

Myxoma virus (MYXV), a member of the Poxviridae family, is the agent responsible for myxomatosis, a highly lethal disease in the European rabbit (Oryctolagus cuniculus). The main anatomical and clinical features of myxomatosis are a pseudotumoral lesion at the inoculation site followed by the occurrence of secondary lesions at cutaneous and visceral levels, named myxomas [29]. Due to MYXV's particular ability to escape and subvert the host artillery, these lesions are accompanied by general dysfunction of cellular immunity, resulting in bacterial super infections of the respiratory tract culminating in death within two weeks [29].

* Corresponding author: c.camus@envt.fr
MYXV has a double-stranded DNA genome of $162 \mathrm{kbp}$ [5], with a central region containing highly conserved enzymatic and structural genes required for the maintenance of essential viral functions. Peripheral regions of the DNA, within and near the inverted terminal repeats (ITR) at both sides of the genome, encode nonessential factors that contribute to the modulation of the host response to infection [29, 31, 32]. Two genes present near the right ITR, M148R and M149R, have functions that are still speculative. They encode 2 of the 4 ankyrin (ANK) repeatcontaining proteins of the MYXV $[5,17]$. The ANK repeat is one of the most common, modular, protein-protein interaction motifs in nature. This module is involved in a wide range of cellular functions. The importance 
of the MYXV-ANK-repeat proteins has been demonstrated: MT-5 is a host-range factor essential for permissive MYXV infection in rabbit lymphocytes [18, 34], and Myxoma Nuclear factor (MNF) seems to interfere with NF-kappa B (NFkB) pathways, leading to the inhibition of inflammatory response [6]. Disruption of either one of these genes results in dramatic attenuation of myxomatosis in infected European rabbits. Interestingly, M148R, M149R, and MNF (M150R) are located in series on the MYXV genome, forming a cluster of ANK repeats encoding genes at the right end of the MYXV genome.

Here we present the first characterization of M148R and M149R. Our data suggest that they are both virulence factors of MYXV, with different cellular localizations and acting in different ways compared to the other ANK repeat MYXV proteins.

\section{MATERIALS AND METHODS}

\subsection{Cells and viruses}

Rabbit kidney cells (RK13; ATCC CCL-37), RK13 HGPRT $^{-}$cells (deficient in hypoxanthineguanine phosphoribosyl transferase) and Baby Green Monkey Kidney cells (BGMK) were maintained in Dulbecco minimum essential medium (DMEM) supplemented with $10 \%$ fetal calf serum (FCS). Rabbit peripheral blood mononuclear cells (PBMC) were isolated and cultured as previously described [23].The wild type MYXV strain T1 and the MYXV mutants (MYXV- $\triangle \mathrm{M} 148 \mathrm{R}$, MYXV$\Delta \mathrm{M} 149 \mathrm{R}$ and MYXV- $\Delta \mathrm{M} 148 \mathrm{R} \Delta \mathrm{M} 149 \mathrm{R})$ were grown in RK13 cells, in DMEM supplemented with $5 \%$ FCS.

\subsection{Cloning, sequencing and computer analysis of DNA and protein sequences}

DNA sequences were analyzed with DNA Strider 1.3 software [15] and the BLAST program [35]. Searches for ANK repeats were performed with $\mathrm{REP}^{1}$ [1]; $\operatorname{Pfam}^{2}$ [11]; and SMART $^{3}$ [14]; online software packages. Manual

${ }^{1}$ http://www.embl-heidelberg.de/ andrade/papers/ rep/search.html

${ }^{2} \mathrm{http}: / /$ pfam.sanger.ac.uk/search

${ }^{3} \mathrm{http}: / /$ smart.embl-heidelberg.de/

Page 2 of 14 (page number not for citation purpose) analysis, according to published consensus promoter sequences [4], was performed to predict M148R and M149R expression during the infection cycle.

\subsection{RNA extraction and RT-PCR analysis}

RK13 cells $\left(2 \times 10^{6}\right.$ cells $)$ were infected with wild type MYXV strain T1 at a multiplicity of infection (m.o.i.) of 5. The inoculum was allowed to adsorb for $1 \mathrm{~h}$ at $4{ }^{\circ} \mathrm{C}$. Total RNA was isolated at $0,2,4,8,12$ and $16 \mathrm{~h}$ post-infection (p.i.) (NucleoSpin RNA II; Macherey-Nagel, Hoerd, France). In addition, total RNA was also extracted at $16 \mathrm{~h}$ p.i. from mock infected cells and from $\mathrm{T} 1$ infected cells treated with $40 \mu \mathrm{g} / \mathrm{mL}$ cytosine arabinoside (AraC) (Sigma, Lyon, France) at the time of infection. All RNA samples were subjected to DNaseI treatment. Reverse transcription was performed using oligo$\mathrm{dT}$ and M-MLV reverse transcriptase (Invitrogen, Paisley, UK), and followed by PCR analysis using specific primers of M148R (5'M148R-BglII (5'-CGAAGATCTATGGATCACGTAAGCTATT ACATTGT-3') and 3'M148R-PstI (5'-AAACTG CAGGTAACCGAACGTATCTATGCAAC- $\overline{\left.3^{\prime}\right) \text { ) }}$ or M149R (5'M149R-BamHI (5'-CGC GGATCC GCAATTATGGCCTCGTTGCAT-3') and $3^{\prime}{ }^{\prime} \mathrm{M}$ 149R-PstI (5'-AAACTGCAGCGCACTATTTTGT ACGGTTTA-3') (restriction sites are underlined). PCR (Expand High Fidelity; Roche, Basel, Switzerland) were performed over 30 cycles, with a hybridization temperature of $63^{\circ} \mathrm{C}$ for each cycle. A control RT-PCR, in which reverse transcriptase was omitted during the RT step, was performed with all samples (not shown).

\subsection{Engineering of Green Fluorescent Protein (GFP) fusions}

GFP fusions, under CMV promoter, were obtained using the pEGFP-F plasmid vector (BD Biosciences-Clontech, Saint-Germain-en-Laye, France). The M148R open reading frame was amplified by PCR using 5'M148RBglII and 3'M148RPstI. The M149R open reading frame was amplified by PCR using 5'M149RBamHI and $3^{\prime}$ M149RPstI. The resulting PCR fragments were inserted between the BgIII and PstI sites in pEGFP-F, thus replacing the farsenylation box-coding sequence downstream of the GFP sequence. The resulting plasmids have been named pCMV-GFPM148R and pCMV-GFPM149R. 
The P7.5 early/late poxviral promoter, issued from pSC11 [7], was digested by Xbal-BamHI and cloned into pBluescript-SK (Stratagene, Massy, France). The resulting plasmid pBS-P7.5 was digested by XmaI and KpnI to insert, under P7.5 poxviral promoter, the entire GFP fusion sequence of M148R or M149R, provided by AgeI-KpnI digestion of pCMV-GFPM148R and pCMV-GFPM149R, respectively. The resulting plasmids are pBS-P7.5GFPM148R and pBSP7.5GFPM149R, respectively.

\subsection{Confocal microscopy observations}

BGMK cells were plated onto multichamber slide flasks (Falcon, Le Pont de Claix, France), transfected with plasmid expressing GFP fusion of M148R or M149R under P7.5 or CMV promoter, with or without prior infection for $2 \mathrm{~h}$ with MYXV deleted for the corresponding gene. Twenty-four hours post-transfection (p.t.), cells were fixed with $4 \%$ paraformaldehyde in PBS and permeabilized with $0.1 \%$ Triton $\mathrm{X}$ 100. Cells were incubated with mouse anti-human B23 antibodies (1/100; Sigma) or anti-MYXV serum $(1 / 500)$ in $0.05 \%$ Tween in PBS and then with rhodamine RX coupled anti-mouse antibodies (1/200; Jackson Immunoresearch, West Grove, PA, USA) or CY-5 coupled anti-rabbit antibodies (1/200; Immunotech, Villepinte, France), respectively. Some samples were stained with TO-PRO-3 iodide (Invitrogen). Samples were observed with a confocal LSM Olympus microscope. Multistaining experiments were performed using the sequential mode.

\subsection{Construction of MYXV- $\Delta M 148 R$, MYXV- $\triangle M 149 R$, MYXV- $\Delta$ M148R $\Delta M 149 R$, and revertant viruses}

Briefly, inactivation of the target open reading frames (M148R, M149R or both) was achieved by homologous recombination in MYXV infected RK13 cells, transfected with the appropriate plasmid. The M149R gene, amplified by PCR (using 5'M149RBamHI and 3'M149RPstI primers) and cloned into the pGEM-T vector (Promega, Charbonnieres, France) was inactivated by replacing the SnaBI-BglII central region (785 bp) by the $L a c Z$ gene, under the control of the late Vaccinia virus promoter P11, issued from pSC11 [7]. After homologous recombination in MYXV T1 infected cells, MYXV- $\triangle$ M149R mutant was screened for blue plaque in the presence of X-Gal (5-bromo-4chloro-3-indolyl- $\beta$-D-galactopyranoside).

M148R gene, amplified by PCR (using 5'M148RBglII and 3'M148RPstI ) and cloned into the pGEM-T expression vector (Promega), was inactivated by replacing the SnaBI-EcoRV central region (1051 bp) by the Ecogpt gene (Escherichia coli xanthine-guanine phosphoribosyl transferase), under the control of the P7.5 promoter issued from the digest of pRBgpt [9]. After recombination in MYXV infected RK13 cells, MYXV- $\Delta$ M148R mutants were selected by resistance to mycophenolic acid in DMEM supplemented with $25 \mu \mathrm{g} / \mathrm{mL}$ mycophenolic acid (MPA), $250 \mu \mathrm{g} / \mathrm{mL}$ xanthine and HAT (Hypoxanthine Aminopterin Thymidine; Sigma, 1/50).

The MYXV- $\Delta$ M148R $\Delta$ M149R was obtained by transfecting MYXV- $\Delta$ M149R infected RK13 cells with the plasmid containing the inactivated form of M148R. MYXV- $\Delta$ M148R $\Delta$ M149R was selected by resistance to mycophenolic acid. Purity of all mutant viruses was verified by PCR.

In order to engineer a revertant virus (MYXVrev), the native sequence including M148R and M149R open reading frames was obtained by PCR using 5'M148RBglII and 3'M149RPstI primers, and cloned into pGEM-T. After recombination in MYXV- $\Delta$ M148R $\Delta$ M149R-infected RK13 HGPRT $^{-}$cells, MYXV-rev was obtained by reverse Ecogpt selection using 6-thioguanine $(5 \mu \mathrm{g} / \mathrm{mL})$ and by reverse white-blue screening.

\subsection{Infection and virus growth curves}

For growth analysis in rabbit PBMC, $6 \times 10^{6}$ cells were infected with T1, MYXV- $\triangle \mathrm{M} 148 \mathrm{R}$, MYXV- $\Delta$ M149R or MYXV- $\Delta$ M148R $\Delta$ M149R at an m.o.i. of 1. For single-step analysis on RK13 and BGMK, $5 \times 10^{5}$ cells were infected with wild type MYXV or mutant viruses at an m.o.i. of 4 . For multi-step analysis on RK13 and BGMK, $5 \times 10^{5}$ cells were infected with viruses at an m.o.i. of 0.01 .

The inoculums were allowed to adsorb for $2 \mathrm{~h}$ at $4{ }^{\circ} \mathrm{C}$. Then, unabsorbed viruses were removed, and cells were incubated in DMEM supplemented with $5 \%$ FCS. At different times p.i., cells were scraped, frozen and virus titers were determined on RK13 cells.

(page number not for citation purpose) Page 3 of 14 
2.8. Infection of rabbits with wild-type MYXV, MYXV-rev, MYXV- $\triangle$ M148R, MYXV- $\Delta M 149 R$ and MYXV- $\Delta$ M148R $\Delta$ M149R

Eight-week old male New Zealand White rabbits were obtained from a local supplier and housed in biocontainment facilities according to the guidelines of the European Community Council on Animal $\mathrm{Care}^{4}$. All procedures on animals were performed by staff accredited by the French Ministry of Agriculture and were designed to limit animal pain and distress. Infections were performed intradermally in the right ear with $5 \times 10^{3} \mathrm{PFU}$ of either virus. Rabbits were monitored daily for clinical signs of myxomatosis. Rabbits that became moribund were sacrificed with T61 (Distrivet, Romainville, France) administered intravenously.

\subsection{Histological examination}

For histological studies, 6 rabbits were inoculated with MYXV strain T1 and 6 were inoculated with each mutant-virus described above. At 5 , 8 , and 13 days p.i., two animals from each group were sacrificed. Two mock-infected rabbits were sacrificed and used as controls. All animals were subjected to complete post-mortem examination. Tissue material from the injection site (ear [primary site]) and parotid lymph node (secondary site) were taken and stored in $10 \%$ neutral formalin for further analysis. After fixation, tissues were routinely processed into paraffin blocks, sectioned at a thickness of $4 \mu \mathrm{m}$, and stained with haematoxylin and eosin for microscopic examination. Lesions were assessed histologically and graded as minimal $(+)$, mild $(++)$, moderate $(+++)$, marked $(++++)$ or severe $(+++++)$.

\section{RESULTS}

\subsection{M148R and M149R are two ANK repeats and F-box containing proteins}

Depending on the software used for protein analysis, up to 10 ANK repeats can be identified in M148R, and up to 9 in M149R (Fig. 1). The newly established PRANC (Pox protein Repeats of Ankyrin C-terminal)

\footnotetext{
${ }^{4}$ European Council directive 86/609/EEC, 24 November 1986.
}

Page 4 of 14 (page number not for citation purpose) domain, belonging to the F-box motif family, is present in both proteins.

\subsection{M148R and M149R are expressed sequentially during the infection}

Manual analysis, according to published consensus promoter and terminator sequences, revealed sequences consistent with a late transcription of M148R. No sequence clearly corresponding to early or late promoter was found upstream of the ATG of M149R.

RT-PCR analysis of total RNA purified from wild-type MYXV-infected cells demonstrated that the M148R transcript was weakly detectable as early as $2 \mathrm{~h}$ p.i.. The expression of M148R increased up to $16 \mathrm{~h}$ p.i. and is totally inhibited in the presence of $\mathrm{AraC}$ (Fig. 2, upper panel).

The M149R transcript was detectable as early as $2 \mathrm{~h}$ p.i., and could still be detected at $16 \mathrm{~h}$ p.i. (Fig. 2, middle panel). However, the level of detected transcript was noticeably lower following the treatment with AraC, as opposed to what was observed with MNF (M150R), control of early gene expression (Fig. 2, lower panel). Since M148R, M149R and $\mathrm{MNF}$ are organized in a cluster of genes, temporally expressed in the reverse sense of their location, one could influence the expression of the others. Therefore, RTPCR analysis of expression of M148R and M149R in T1 $\mathrm{MNF}$-infected RK13 cells was performed. MNF deletion affects neither M148R nor M149R transcription (data not shown). Likewise, deletion of M149R does not affect M148R transcription.

\subsection{M148R and M149R have different subcellular localizations}

To determine the subcellular localization of each protein, plasmids expressing a GFP-protein fusion (with M148R or M149R fused downstream of the GFP, under CMV promoter) were used to transfect BGMK cells. Cells were examined by confocal microscopy at $24 \mathrm{~h}$ p.t.. As shown in Figure 3Aa, GFPM148R fusion is located in both the cytoplasm and nucleus. The nuclear fraction of M148R 
$\underline{\mathbf{A}}$

\begin{tabular}{|c|c|c|c|c|c|c|c|c|c|}
\hline \multicolumn{5}{|c|}{ M148R } & \multicolumn{5}{|c|}{ M149R } \\
\hline \multirow{2}{*}{ Position } & \multirow{2}{*}{ Motif } & \multicolumn{3}{|c|}{ Method } & \multirow{2}{*}{ Position } & \multirow{2}{*}{ Motif } & \multicolumn{3}{|c|}{ Method } \\
\hline & & Pfam & REP & SMART & & & Pfam & REP & SMART \\
\hline $39-70$ & Ank & & $x$ & & $2-34$ & Ank & & $x$ & $x$ \\
\hline $113-144$ & Ank & $x$ & $x$ & $x$ & $37-68$ & Ank & $x$ & $x$ & $x$ \\
\hline 148-179 & Ank & $x$ & & $x$ & 71-106 & Ank & $\times($ trunc $)$ & $x$ & $x$ \\
\hline $184-215$ & Ank & $x$ & $x$ & $x$ & $110-142$ & Ank & $\times$ & $x$ & $x$ \\
\hline $256-290$ & Ank & $x$ & $x$ & $x$ & $146-178$ & Ank & $x$ & $x$ & $x$ \\
\hline $295-328$ & Ank & $x$ & $x$ & $x$ & $183-216$ & Ank & $x$ & $x$ & $x$ \\
\hline $330-361$ & Ank & $x$ & $x$ & $x$ & $252-281$ & Ank & $x$ & $x$ & $x$ \\
\hline $365-398$ & Ank & $x$ & $x$ & $x$ & $285-314$ & Ank & $x$ & $x$ & $x$ \\
\hline $442-471$ & Ank & $x$ & $x$ & $x$ & $325-352$ & Ank & & $x$ & \\
\hline $475-504$ & Ank & & $x$ & $x$ & $384-480$ & PRANC & $x$ & & $x$ \\
\hline $570-664$ & PRANC & $x$ & & $x$ & & & & & \\
\hline
\end{tabular}

B

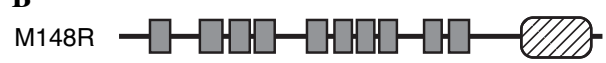

\section{M149R}

Figure 1. Functional domains of M148R and M149R Myxoma virus proteins. (A) Functional domains of M148R and M149R proteins found by 3 online software: Pfam [11], REP [1] and SMART [14]. "trunc" (truncated) indicates that only the second half of the repeat was identified. (B) Schematic representation of M148R and M149R proteins. Gray boxes: ANK repeat; hatched: PRANC (Pox protein Repeats of Ankyrin C-terminal) domain.

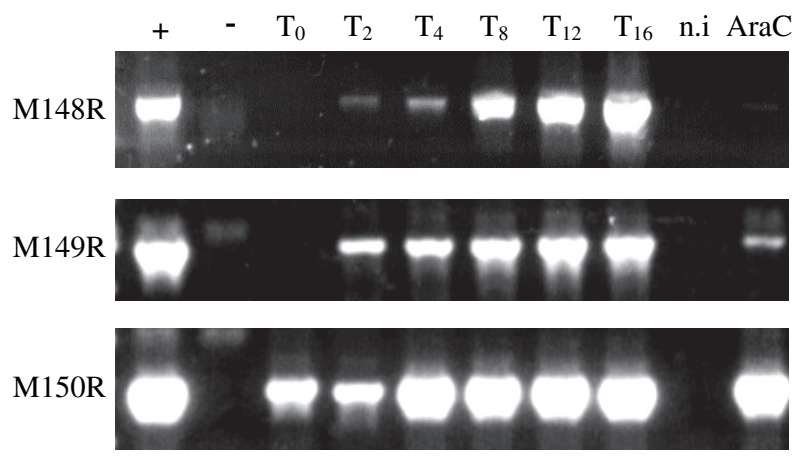

Figure 2. Expression of M148R and M149R mRNA in cell culture. RK13 cells were infected with wild type MYXV. At different times p.i., mRNA were extracted, subjected to reverse transcription using oligodT primers, following which, PCR was performed using specific primers for M148R, M149R, or M150R. Lane + , positive control, i.e. PCR on T1 DNA; lane -, negative control, i.e. PCR without template; lanes $\mathrm{T}_{0}$ through $\mathrm{T}_{16}$, cells infected with wild-type MYXV for $0,2,4,8,12$, or $16 \mathrm{~h}$, respectively; lane n.i., mockinfected cells; lane AraC, cells infected with wild-type MYXV for $16 \mathrm{~h}$ and incubated with $\mathrm{AraC}$ at the time of infection. $\mathrm{T}_{0}$ corresponds to RNA extractions performed after $1 \mathrm{~h}$ of virus adsorption. 
A

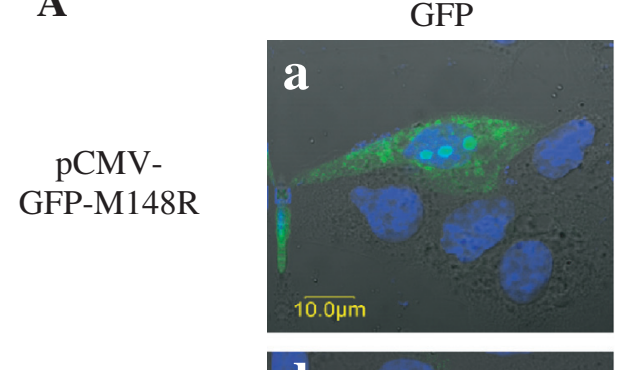

pCMVGFP-M149R

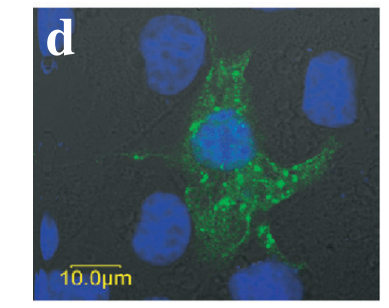

B

pBS-P7.5 GFP-M148R

pBS-P7.5 GFP-M149R
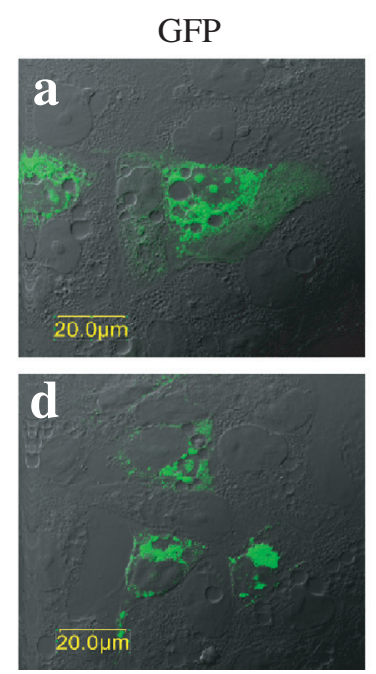

Anti-B23
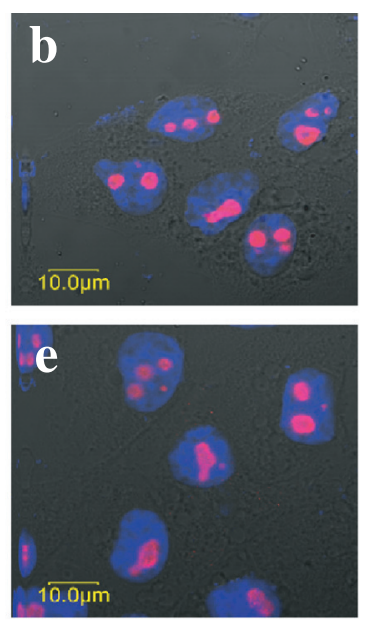

Anti-MYXV
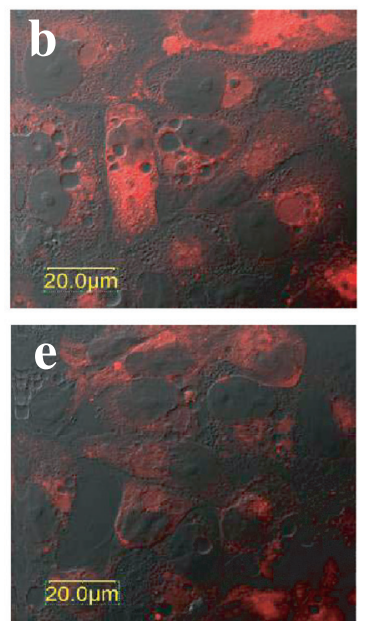
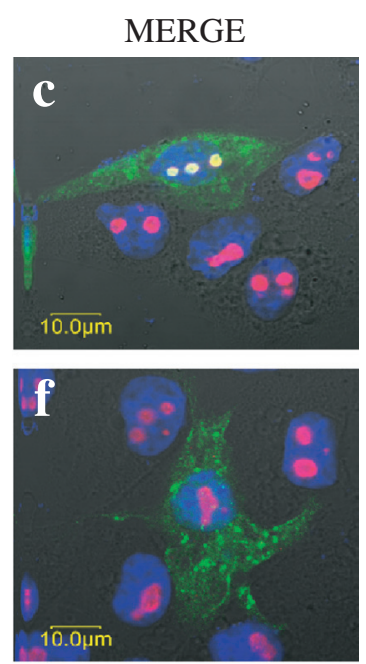

MERGE
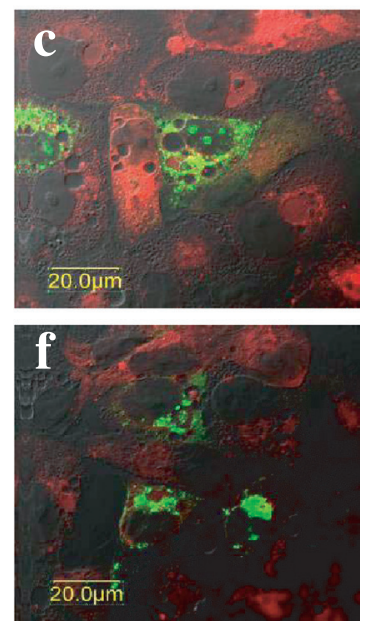

Figure 3. Cellular localization of M148R and M149R. (A) BGMK cells grown on coverslips were transfected with pCMV-GFPM148R (a, b, c) or pCMV-GFPM149R (d, e, f). Cells were fixed at 24 h p.t., permeabilized, stained with anti-B23 antibody (red staining) and TO-PRO-3 iodide to detect nuclei (blue staining), and analyzed by confocal microscopy with a $60 \times$ objective. Multistaining experiments were performed using the sequential mode. (B) BGMK cells grown on coverslips were pBS-P7.5GFPM148R (a, b, c) or pBS-P7.5GFPM149R (d, e, f) transfected, with prior $2 \mathrm{~h}$ infection with the MYXV deleted for the corresponding gene. At 24 h p.t., cells were fixed, permeabilized, stained with anti-MYXV serum (red staining) and analyzed by confocal microscopy as previously indicated.

shows a nucleolar pattern, as confirmed by colocalization (Fig. 3Ac, yellow merge staining) with B23 (nucleophosmin, Fig. 3Ab, red staining), a major multifunctional nucleolar phosphoprotein. A punctuate pattern with a uniform distribution in the cytoplasm was observed with the GFP-M149R fusion (Fig. 3Ad). It was not possible to show any 
colocalization with the endoplasmic reticulum, early endosomes, or lysosome (data not shown). Typical diffuse (cytoplasmic and nuclear) green pattern was observed with the control transfection with a GFP expressing plasmid (data not shown).

The same patterns were observed in an infectious context, with GFP-fusions expressed under $\mathrm{P} 7.5$ poxviral promoter (Fig. 3B). Absence of green staining in BGMK transfected with pBS-7.5GFPM148R or pBS7.5GFPM149R without infectious context confirmed that fusion expression under the P7.5 promoter requires MYXV infection (data not shown).

\subsection{M148R and M149R are not essential for replication in classical MYXV permissive cells}

The role of M148R and M149R in the replication of MYXV was evaluated by engineering mutant viruses deleted in either M148R (MYXV-DM148R), or M149R (MYXV- $\triangle$ M149R), or both (MYXV- $\Delta$ M148R $\Delta$ M149R). The capacity of replication of mutant viruses in cultured cell lines (RK13 and BGMK) and primary cells (PBMC) was tested. Experiments showed that neither deletion of M148R, nor M149R, nor both, induced modification in virus replication in RK13, BGMK, or PBMC (Fig. 4A). In order to examine mutant viruses spread in cultured cells, multi-step experiments on RK13 and BGMK cells were performed. No defects in the ability of mutant viruses to spread in these cells were observed (Fig. 4B).

\subsection{M148R and M149R are new MYXV virulence factors in European rabbits}

To evaluate the role of M148R and M149R in the pathobiology of MYXV, European rabbits were inoculated intradermally with either wild type MYXV strain T1, MYXV- $\Delta$ M148R, MYXV- $\Delta$ M149R, MYXV- $\Delta$ M148R $\Delta$ M149R, or MYXV-rev (control of phenotype specificity). The clinical course of infection was monitored daily for 21 days. Data are summarized in Table I. Rabbits infected with the T1 strain developed typical clinical myxomatosis, characterized by the development at day 4 p.i. of a large red and raised primary skin lesion at the inoculation site. At day 8 p.i., secondary lesions appeared on ears, eyelids, nose, back and subsequentially over the entire body. Conjunctivas inflammation and initially serous, later mucopurulent (day 10 p.i.) discharge from the nose and eyes followed, accompanied by respiratory distress (day 12 p.i.). Rabbits died within two weeks due to bacterial infection of the respiratory tract. The same clinical course of infection was observed with MYXV-rev infected rabbits.

Clinical observations revealed that infection with the MYXV- $\triangle$ M148R, MYXV- $\Delta$ M149R and MYXV- $\Delta$ M148R $\Delta$ M149R mutants is clearly attenuated compared to wild type virus infection. The MYXV- $\Delta M 148 \mathrm{R}$ infected group showed a delay of three days in the onset of clinical signs, with a mortality rate of $40 \%$. They suffered from only light infections of conjunctivas and respiratory tract. MYXV- $\triangle$ M149R induced a delay of 4 days on the onset of secondary lesions, which were less numerous and restricted to the face area. All infected animals recovered. Finally, all rabbits infected with the MYXV$\triangle \mathrm{M} 148 \mathrm{R} \Delta \mathrm{M} 149 \mathrm{R}$ showed few clinical signs, except for secondary lesions which appeared earlier (day 6 p.i.) than usual, were smaller and more numerous, and finally resorbed rapidly. All rabbits recovered.

\subsection{Histological analysis of lesions from wild type and mutant MYXV}

Detailed histological examination of tissue material from both the primary (ear) and secondary (parotid lymph node) infection sites was carried out at various times during the course of infection. The results of the complete analysis are summarized in Table II.

At day 5 p.i., the injection sites of wild-type MYXV and mutant viruses demonstrated similar microscopic lesions, i.e. perivascular dermatitis with focal edema, interstitial mucinosis and inflammatory infiltrates mainly composed of heterophils. In the parotid lymph node, both mutant and wild-type viruses induced a 
$\mathbf{A}$
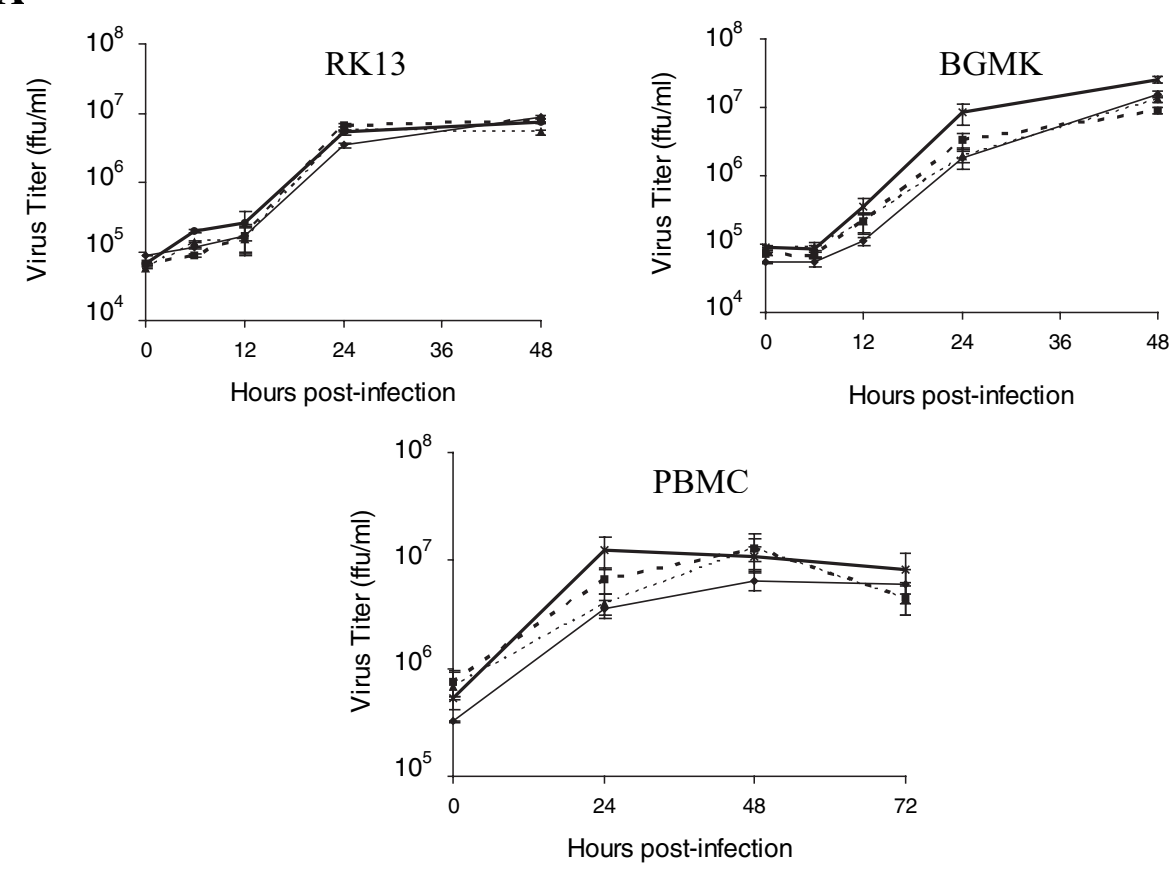

B
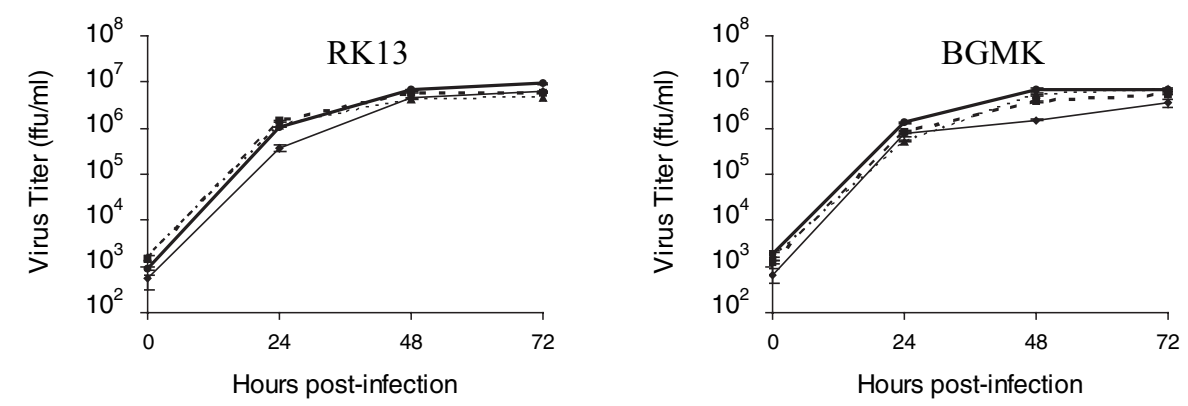

Figure 4. Growth kinetics of wild-type and mutant viruses. (A) To evaluate viruses in vitro replication, cell lines (RK13 and BGMK) and primary cells (PBMC) were respectively infected at m.o.i. 4 and m.o.i. 1, with wild-type MYXV (thin solid line ( $\square$ )), MYXV- $\triangle$ M148R (bold dashed line ( $\square$ )), MYXV- $\Delta$ M149R (thin dashed line $(\mathbf{\Delta})$ ) or MYXV- $\triangle$ M148R $\Delta$ M149R (bold solid line $(\times)$ ). Virus titers were determined at different times p.i. on RK13 cells. Results are shown as means \pm SEM (triplicate). (B) To examine virus spread, cells were infected at a low m.o.i. $($ m.o.i. $=0.01)$. Virus titers were determined at different times p.i. as indicated above. Results are shown as means \pm SEM (duplicate).

lymphadenitis with lymphoid hyperplasia, focal histiocytosis and moderate infiltration by heterophils.

At day 8 p.i., the injection sites of wild-type MYXV, MYXV- $\Delta$ M148R and
MYXV- $\Delta$ M148R $\Delta$ M149R showed a difference in the nature of inflammatory infiltrates in the myxomas. With wild-type MYXV (as with the MYXV- $\Delta$ M149R, to a lesser extent), heterophils still composed the main 
Table I. Pathogenesis of M148R and M149R in European rabbits.

\begin{tabular}{|c|c|c|c|c|}
\hline \multirow[t]{2}{*}{ Days p.i. } & \multicolumn{4}{|c|}{ Clinical signs following virus infection } \\
\hline & Wild-type MYXV and MYXV-rev & MYXV- $\Delta$ M148R & MYXV- $\Delta$ M149R & MYXV- $\Delta$ M148R $\Delta$ M149R \\
\hline 0 & $\begin{array}{c}\text { Intradermal inoculation } \\
\text { of } 5 \text { rabbits with } 5000 \mathrm{PFU} \\
\text { of virus }\end{array}$ & $\begin{array}{l}\text { Intradermal inoculation } \\
\text { of } 5 \text { rabbits with } 5000 \mathrm{PFU} \\
\text { of virus }\end{array}$ & $\begin{array}{l}\text { Intradermal inoculation } \\
\text { of } 5 \text { rabbits with } 5000 \mathrm{PFU} \\
\text { of virus }\end{array}$ & $\begin{array}{l}\text { Intradermal inoculation of } 5 \text { rabbits } \\
\text { with } 5000 \text { PFU of virus }\end{array}$ \\
\hline $4-6$ & $\begin{array}{l}\text { Primary lesions at inoculation } \\
\text { sites: raised, soft, red } \\
\text { (ca. } 1 \text { to } 2 \mathrm{~cm})(5 / 5)^{*}\end{array}$ & $\begin{array}{l}\text { Primary lesions at inoculation } \\
\text { sites: raised, soft, red } \\
(\mathrm{ca} .<1 \mathrm{~cm})(5 / 5)^{*}\end{array}$ & $\begin{array}{c}\text { Primary lesions at } \\
\text { inoculation sites: raised, } \\
\text { soft, red (ca. } 1 \text { to } 2 \mathrm{~cm}) \\
(5 / 5)^{*}\end{array}$ & $\begin{array}{l}\text { Primary lesions at inoculation sites: } \\
\text { raised, soft, red (ca. } 1 \text { to } 2 \mathrm{~cm} \text { ), } \\
\text { multiple secondary lesions on ears } \\
\quad(\mathrm{ca}<1 \mathrm{~cm})(5 / 5)^{*}\end{array}$ \\
\hline 8 & $\begin{array}{l}\text { Large and diffused primary } \\
\text { myxomas, secondary infections of } \\
\text { conjunctivas and respiratory tract, } \\
\text { dyspnea, and multiple secondary } \\
\text { lesions on face, ears, back and } \\
\text { testis }(5 / 5)^{*}\end{array}$ & $\begin{array}{l}\text { Large and diffused primary } \\
\text { myxomas, secondary light } \\
\text { infections of conjunctivas }(4 / 5) \text {, } \\
\text { secondary lesions on ears }(5 / 5)^{*}\end{array}$ & $\begin{array}{l}\text { Primary myxoma resorbed, } \\
\text { secondary infections of } \\
\text { conjunctivas and } \\
\text { respiratory tract, no } \\
\text { secondary lesions }(5 / 5)^{*}\end{array}$ & $\begin{array}{l}\text { Myxoma resorbed }(5 / 5)^{*} \text {, light } \\
\text { infections of conjunctivas and } \\
\text { respiratory tract }(4 / 5)^{*}\end{array}$ \\
\hline 14 & $\begin{array}{l}\text { Multiple secondary lesions, } \\
\text { turning necrotic. All rabbits } \\
\text { sacrificed due to increased severity } \\
\text { of the clinical signs }(5 / 5)^{*}\end{array}$ & $\begin{array}{l}\text { Myxomas resorbed, secondary } \\
\text { infections of conjunctivas and } \\
\text { respiratory tract }(4 / 5)^{*}\end{array}$ & $\begin{array}{l}\text { Secondary lesions on ears, } \\
\text { secondary infections of } \\
\text { conjunctivas and } \\
\text { respiratory tract }(5 / 5)^{*}\end{array}$ & Rabbits recovered $(5 / 5)^{*}$ \\
\hline 21 & & 2 rabbits euthanized & Rabbits recovered $(5 / 5)^{*}$ & \\
\hline
\end{tabular}

* Number of rabbits suffering from clinical signs described / total number of rabbits infected with corresponding virus. 
Table II. Histological observations of lesions from rabbits infected with wild-type or mutant viruses. All animals were subjected to a complete post-mortem examination. Tissue materials were from the injection site (ear [primary site]) and parotid lymph node (secondary site).

Clinical signs

$$
\begin{array}{cc}
\text { Lesion intensity }{ }^{\mathrm{a}} \text { with the indicated virus } \\
\text { Day 5 p.i. }
\end{array}
$$

Day 13 p.i.

MYXV- MYXV- Wild- MYXV- MYXV- MYXV- Wild- MYXV- MYXV- MYXV-

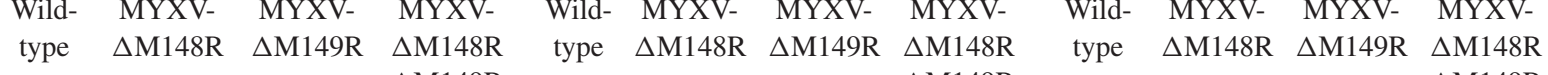
$\triangle \mathrm{M} 149 \mathrm{R}$ $\triangle \mathrm{M} 149 \mathrm{R}$ $\triangle \mathrm{M} 149 \mathrm{R}$

Primary site ${ }^{\mathrm{b}}$ : Perivascular

R

dermatitis

Epidermal spongiosis and

vesicles

\begin{tabular}{|c|c|c|c|c|c|c|c|c|c|c|c|c|}
\hline Edema & +++ & +++ & $+++/++++$ & $++/+++$ & ++++ & +++ & ++ & ++ & +++ & ++ & +++ & ++ \\
\hline $\begin{array}{l}\text { Focal interstitial } \\
\text { microhaemorrages }\end{array}$ & - & + & ++ & - & ++ & + & ++ & + & ++ & - & +++ & - \\
\hline Focal thrombosis & + & + & - & + & ++ & + & ++ & + & - & - & ++ & + \\
\hline Heterophils & $++/+++$ & $++/+++$ & $++/+++$ & $++/+++$ & ++++ & ++ & +++ & ++ & +++ & + & ++ & + \\
\hline Mononuclear cells & + & + & + & + & ++ & ++++ & ++ & ++++ & +++ & ++++ & +++ & ++++ \\
\hline Activated fibroblasts & ++ & ++ & ++ & ++ & +++ & +++ & +++ & +++ & +++++ & +++ & +++ & +++ \\
\hline $\begin{array}{l}\text { Interstitial mucinosis } \\
\text { econdary sites : } \\
\text { ymphadenitis }\end{array}$ & +++ & +++ & +++ & ++ & +++ & ++ & +++ & +++ & ++++ & ++ & +++ & ++ \\
\hline Lymphodepletion & - & - & - & - & - & - & - & - & & - & - & - \\
\hline Lymphoid hyperplasia & $++/+++$ & ++ & ++ & ++ & +++ & +++ & +++ & ++ & & ++ & ++ & ++ \\
\hline Focal histiocytosis & ++++ & +++ & $+++/++++$ & ++/+++ & +++ & +++ & +++ & +++ & & ++ & +++ & $+/-$ \\
\hline Infiltration by heterophils & +++ & +++ & +++ & ++ & +++ & ++ & +++ & + & & - & + & - \\
\hline Activated fibroblasts & - & - & - & - & +++ & ++ & ++ & + & & - & + & - \\
\hline Interstitial mucinosis & - & - & - & - & +++ & + & + & + & & - & - & - \\
\hline
\end{tabular}

${ }^{\text {a }}$ Lesion intensity: +, minimal; ++, mild; +++, moderate; ++++, marked or +++++, severe.

${ }^{\mathrm{b}}$ Samples were taken from lesions at the inoculation site (ear).

c Samples were taken from parotid lymph nodes. Main cells of inflammatory response are highlighted. 
cellular population. By contrast, for the lesions associated with the MYXV- $\triangle \mathrm{M} 148 \mathrm{R}$ and MYXV- $\Delta$ M148R $\Delta$ M149R, sequential inflammatory cellular reactions progressed more rapidly, as attested by the presence of infiltrates with a majority of mononuclear cells (histiocytes and lymphocytes). In the parotid lymph node, a lymphadenitis with lymphoid hyperplasia and focal histiocytosis was observed for all viruses. As for the primary site, infiltration by heterophils was more pronounced for wild-type MYXV and MYXV- $\Delta$ M149R than for MYXV- $\Delta$ M148R and MYXV- $\Delta$ M148R $\Delta$ M149R. The presence of activated fibroblasts with interstitial mucinosis was greater with wild-type MYXV than with all other viruses.

At day 13 p.i., the injection sites of wild-type MYXV, MYXV-DM148R and MYXV- $\Delta$ M148R $\Delta$ M149R still showed a difference in the nature of inflammatory infiltrates in the myxomas. With wild-type MYXV as with MYXV- $\triangle \mathrm{M} 149 \mathrm{R}$, the proportions of heterophils and mononuclear cells (histiocytes, lymphocytes, and plasmocytes) tended to become counterbalanced. For the lesions associated with MYXV- $\Delta \mathrm{M} 148 \mathrm{R}$ and MYXV- $\triangle \mathrm{M} 148 \mathrm{R} \Delta \mathrm{M} 149 \mathrm{R}$, mononuclear cells were markedly predominant. The number of activated fibroblasts and the amount of interstitial mucinosis were greater with wildtype MYXV than with all other viruses. In the parotid lymph node, both mutant and wildtype viruses showed a lymphadenitis with lymphoid hyperplasia and focal histiocytosis.

From these observations, we can conclude that the inflammatory reaction is more rapidly resolved for MYXV- $\triangle \mathrm{M} 148 \mathrm{R}$ and MYXV$\triangle \mathrm{M} 148 \mathrm{R} \Delta \mathrm{M} 149 \mathrm{R}$ (at day 8 p.i., mononuclear cells were predominant) than for wildtype MYXV and MYXV-AM149R. Another difference was the very high level of cellular density of activated fibroblasts and interstitial mucinosis in lesions induced by wild-type MYXV at day 13 p.i. in comparison with lesions induced by other viruses.

\section{DISCUSSION}

This study is the first characterization of M148R and M149R, 2 of the 4 ANK repeat proteins encoded by MYXV. We demonstrate that M148R and M149R are virulence factors of MYXV.

Our experiments provide new data on M148R and M149R expression. They were first described as early genes coding for cytoplasmic proteins with 9 ANK repeats and 4 putative transmembrane regions and with 8 ANK repeats, respectively [5]. We show that M148R is expressed as a late gene and that up to 10 ANK repeats can be identified in the protein. We also show that M149R is expressed earlier than M148R, is partially inhibited by $\mathrm{AraC}$ and that up to 9 ANK repeats can be identified in the protein. The observed decrease in M149R expression level, due to AraC treatment, suggests that M149R expression level partially relies on viral DNA replication. No sequence clearly corresponding to early or late promoters was found upstream of the ATG of M149R. However, the GG dinucleotide can be found immediately after a TAATAT motif (a part of the ATG), compatible with an intermediate signal. On the contrary, an early transcription termination signal is present two nucleotides upstream of the stop codon. Interestingly, the M148R and M149R form, with MNF, a cluster of genes coding for ANK repeat proteins, temporally expressed in the reverse sense of their location, without a transcriptional effect from the ones on the others.

M148R and M149R were predicted to be cytoplasmic proteins [5]. This was confirmed for M149R. In contrast we show that M148R is located in both the cytoplasm and nucleolus, with or without a viral context. This suggests that no viral cofactor is required to address M148R to the nucleolus. Though no classical nuclear localization signal (NLS) was identified in M148R, it has been shown that ANK repeats can be used as a non typical NLS [24]. This has been verified for MNF since deletion of its eighth ANK repeat prevents MNF translocation to the nucleus [6]. This may also be the case for M148R.

As initial studies on poxviral ANK repeat proteins, such as Vaccinia virus K1L [3, 22] and M-T5 [18], have demonstrated they were involved in cell tropism or host range 
functions, the role of M148R and M149R in the replication of MYXV was evaluated. We show that deletion of M148R, M149R, or both, does not induce modification in virus replication in rabbit cells (fibroblast cell lines or PBMC) or in BGMK cells. Thus M148R and M149R do not seem to be implicated in either cell tropism or host range functions, based upon the cell lines examined.

However, we show that single deletion of M148R or M149R induces a delay in the onset of blepharitis and respiratory infections, an increase of survival time and a dramatic decrease in mortality rate. Moreover, MYXV$\triangle \mathrm{M} 148 \mathrm{R} \Delta \mathrm{M} 149 \mathrm{R}$ infected rabbits expressed only moderate blepharitis, no signs of respiratory infection and totally recovered. Since there are no significant differences between virus replication in rabbit lymphocytes, we can conclude that the observed delay in clinical sign onset and the attenuated phenotype cannot be explained by impairment of virus diffusion after intradermal infection. MYXV$\triangle \mathrm{M} 149 \mathrm{R}$ induced few secondary lesions that appeared later than with the other viruses and were located on the face only. Surprisingly, MYXV- $\Delta$ M148R $\Delta$ M149R infected rabbits had earlier, smaller and more numerous secondary lesions that resorbed faster than rabbits infected with other viruses, including the wild type one. Therefore, clinical signs observed after infection with MYXV$\triangle \mathrm{M} 148 \mathrm{R} \Delta \mathrm{M} 149 \mathrm{R}$ seem to be different from the simple addition effect of attenuated phenotypes induced by each single deleted virus. This suggests that M148R and M149R may act in synergy.

Histological analysis of the primary myxoma (inoculation site) and parotid lymph node showed that deletion of the M148R gene allowed a quicker resolution of the inflammation. Therefore, like MNF, M148R is located in the cell nucleus and seems to play a role in the subverting of inflammatory response by MYXV. However, deletion of MNF induces more drastic attenuation than M148R deletion and they do not seem to be located in the same subnuclear compartment [6]. Indeed M148R is located in part in the nucleolus of infected cells. For many years, the exclusive function of the nucleolus was thought to be ribosomal rRNA synthesis and ribosome biogenesis. However, the nucleolus has been recently implicated in many aspects of cell biology that include functions such as gene silencing, senescence and cell cycle regulation [1921]. Numerous viruses encode proteins that interfere with the nucleolus, such as EBNA5 of the Epstein Barr virus [30], ICP27 of the Herpes simplex virus [16] or Rev and Tat of HIV-1 [8, 10, 26]. However, reasons for targeting host-cell nucleoli and mechanisms used to subvert nucleolar functions are usually speculative. It may favor viral transcription, translation or alter the cell cycle in order to promote virus replication.

If ANK repeat proteins are involved in a large set of functions, the conserved role of the ANK motif is to be a mediator of specific protein-protein interactions. As the majority of ANK repeats poxviral proteins, M148R and M149R have an F-box sequence at the C-terminus. Both motifs are rare among viruses but are abundant in poxviruses [2, 17]. Moreover, poxviral F-box motifs are not typical compared to those found in eukaryotes for which F-box motifs are located at the $\mathrm{N}$-terminus of the protein and are associated with WD repeats and leucine-rich repeats as classical protein-protein interaction domain [12]. F-box proteins are involved in ubiquitin-dependent proteolysis in cell cycle regulation and signal transduction. They are recognition subunits of ubiquitin ligase complexes where the F-box domain binds to ubiquitin ligase and where proteinprotein interaction domain binds the substrate protein [13]. Based on these observations, Mercer et al. proposed that poxviral ANK-Fbox proteins work as described, using ANK repeats to interact with the target protein and to direct its ubiquitination [17]. It was confirmed for the VACV 68k protein [28] and for five Orf virus proteins [27]. All these ANK-F-box poxviral proteins co-precipitated with Skp1 and Cullin-1, two components of SCF1 ubiquitin ligase complex. All these proteins have different localizations such as cytoplasmic, nuclear, perinucleolar, but none has been shown to be nucleolar as 
is M148R. We attempted to co-precipitate Cullin-1 in BGMK cells transfected with the GFP fusion of M148R and M149R, under CMV promoter. We succeeded in precipitating the fusion proteins, but failed to demonstrate any interaction with neither Cullin-1 nor Skp1 (data not shown). These experiments are not conclusive enough to totally exclude an interaction between these proteins. New experiments should be done in conditions of infection, in primate and rabbit cells. Moreover, possible interactions with other partners known to interact with some ANKF-box poxviral proteins such as proteins of Akt pathway [33] or mainly NFKB signaling pathway, as is the case for $\mathrm{K} 1 \mathrm{~L}$ [25] and MNF [6], need to be explored.

Acknowledgements. We thank Brigitte Peralta and Josyane Loupias for excellent technical assistance. S. Blanié was supported by funds from the French Ministry of Research and Technology.

\section{REFERENCES}

[1] Andrade M.A., Ponting C.P., Gibson T.J., Bork P., Homology-based method for identification of protein repeats using statistical significance estimates, J. Mol. Biol. (2000) 298:521-537.

[2] Bork P., Hundreds of ankyrin-like repeats in functionally diverse proteins: mobile modules that cross phyla horizontally?, Proteins (1993) 17:363-374.

[3] Bradley R.R., Terajima M., Vaccinia virus K1L protein mediates host-range function in RK-13 cells via ankyrin repeat and may interact with a cellular GTPase-activating protein, Virus Res. (2005) 114:104-112.

[4] Broyles S.S., Vaccinia virus transcription, J. Gen. Virol. (2003) 84:2293-2303.

[5] Cameron C., Hota-Mitchell S., Chen L., Barrett J., Cao J.X., Macaulay C., et al., The complete DNA sequence of myxoma virus, Virology (1999) 264:298318 .

[6] Camus-Bouclainville C., Fiette L., Bouchiha S. Pignolet B., Counor D., Filipe C., et al., A virulence factor of myxoma virus colocalizes with NF-kappaB in the nucleus and interferes with inflammation, J. Virol. (2004) 78:2510-2516.

[7] Chakrabarti S., Brechling K., Moss B., Vaccinia virus expression vector: coexpression of betagalactosidase provides visual screening of recombinant virus plaques, Mol. Cell. Biol. (1985) 5:3403-3409.
[8] Dundr M., Leno G.H., Hammarskjold M.L., Rekosh D., Helga-Maria C., Olson M.O., The roles of nucleolar structure and function in the subcellular location of the HIV-1 Rev protein, J. Cell Sci. (1995) 108:2811-2823.

[9] Falkner F.G., Moss B., Transient dominant selection of recombinant vaccinia viruses, J. Virol. (1990) 64:3108-3111.

[10] Fankhauser C., Izaurralde E., Adachi Y., Wingfield P., Laemmli U.K., Specific complex of human immunodeficiency virus type $1 \mathrm{rev}$ and nucleolar B23 proteins: dissociation by the Rev response element, Mol. Cell. Biol. (1991) 11:2567-2575.

[11] Finn R.D., Tate J., Mistry J., Coggill P.C., Sammut S.J., Hotz H.R., et al., The Pfam protein families database, Nucleic Acids Res. (2008) 36:D281-288.

[12] Jin J., Cardozo T., Lovering R.C., Elledge S.J., Pagano M., Harper J.W., Systematic analysis and nomenclature of mammalian F-box proteins, Genes Dev. (2004) 18:2573-2580.

[13] Jin J., Ang X.L., Shirogane T., Wade Harper J., Identification of substrates for F-box proteins, Methods Enzymol. (2005) 399:287-309.

[14] Letunic I., Copley R.R., Pils B., Pinkert S., Schultz J., Bork P., SMART 5: domains in the context of genomes and networks, Nucleic Acids Res. (2006) 34:D257-D260.

[15] Marck C., 'DNA Strider': a 'C' program for the fast analysis of DNA and protein sequences on the Apple Macintosh family of computers, Nucleic Acids Res. (1988) 16:1829-1836.

[16] Mears W.E., Lam V., Rice S.A., Identification of nuclear and nucleolar localization signals in the herpes simplex virus regulatory protein ICP27, J. Virol. (1995) 69:935-947.

[17] Mercer A.A., Fleming S.B., Ueda N., F-box-like domains are present in most poxvirus ankyrin repeat proteins, Virus Genes (2005) 31:127-133.

[18] Mossman K., Lee S.F., Barry M., Boshkov L., McFadden G., Disruption of M-T5, a novel myxoma virus gene member of poxvirus host range superfamily, results in dramatic attenuation of myxomatosis in infected European rabbits, J. Virol. (1996) 70:43944410 .

[19] Olson M.O., Dundr M., Szebeni A., The nucleolus: an old factory with unexpected capabilities, Trends Cell Biol. (2000) 10:189-196.

[20] Olson M.O., Hingorani K., Szebeni A., Conventional and nonconventional roles of the nucleolus, Int. Rev. Cytol. (2002) 219:199-266.

[21] Pederson T., The plurifunctional nucleolus, Nucleic Acids Res. (1998) 26:3871-3876.

(page number not for citation purpose) Page 13 of 14 
[22] Perkus M.E., Goebel S.J., Davis S.W., Johnson G.P., Limbach K., Norton E.K., Paoletti E., Vaccinia virus host range genes, Virology (1990) 179:276-286.

[23] Pignolet B., Boullier S., Gelfi J., Bozzetti M., Russo P., Foulon E., et al., Safety and immunogenicity of myxoma virus as a new viral vector for small ruminants, J. Gen. Virol. (2008) 89:1371-1379.

[24] Sachdev S., Hoffmann A., Hannink M., Nuclear localization of IkappaB alpha is mediated by the second ankyrin repeat: the IkappaB alpha ankyrin repeats define a novel class of cis-acting nuclear import sequences, Mol. Cell. Biol. (1998) 18:2524-2534.

[25] Shisler J.L., Jin X.L., The vaccinia virus K1L gene product inhibits host NF-kappaB activation by preventing IkappaBalpha degradation, J. Virol. (2004) 78:3553-3560.

[26] Siomi H., Shida H., Maki M., Hatanaka M., Effects of a highly basic region of human immunodeficiency virus Tat protein on nucleolar localization, J. Virol. (1990) 64:1803-1807.

[27] Sonnberg S., Seet B.T., Pawson T., Fleming S.B. Mercer A.A., Poxvirus ankyrin repeat proteins are a unique class of F-box proteins that associate with cellular SCF1 ubiquitin ligase complexes, Proc. Natl. Acad. Sci. USA (2008) 105:10955-10960.

[28] Sperling K.M., Schwantes A., Schnierle B.S., Sutter G., The highly conserved orthopoxvirus $68 \mathrm{k}$ ankyrin-like protein is part of a cellular SCF ubiquitin ligase complex, Virology (2008) 374:234-239.

[29] Stanford M.M., Werden S.J., McFadden G., Myxoma virus in the European rabbit: interactions between the virus and its susceptible host, Vet. Res. (2007) 38:299-318.

[30] Szekely L., Jiang W.Q., Pokrovskaja K., Wiman K.G., Klein G., Ringertz N., Reversible nucleolar translocation of Epstein-Barr virus-encoded EBNA-5 and hsp70 proteins after exposure to heat shock or cell density congestion, J. Gen. Virol. (1995) 76:24232432.

[31] Upton C., Macen J.L., McFadden G., Mapping and sequencing of a gene from myxoma virus that is related to those encoding epidermal growth factor and transforming growth factor alpha, J. Virol. (1987) 61:1271-1275.

[32] Upton C., Macen J.L., Maranchuk R.A., DeLange A.M., McFadden G., Tumorigenic poxviruses: fine analysis of the recombination junctions in malignant rabbit fibroma virus, a recombinant between Shope fibroma virus and myxoma virus, Virology (1988) 166:229-239.

[33] Werden S.J., Barrett J.W., Wang G., Stanford M.M., McFadden G., M-T5, the ankyrin repeat, host range protein of myxoma virus, activates Akt and can be functionally replaced by cellular PIKE-A, J. Virol. (2007) 81:2340-2348.

[34] Werden S.J., McFadden G., The role of cell signaling in poxvirus tropism: the case of the MT5 host range protein of myxoma virus, Biochim. Biophys. Acta (2008) 1784:228-237.

[35] Wheeler D.L., Barrett T., Benson D.A., Bryant S.H., Canese K., Chetvernin V., et al., Database resources of the National Center for Biotechnology Information, Nucleic Acids Res. (2008) 36:D13-D21. 